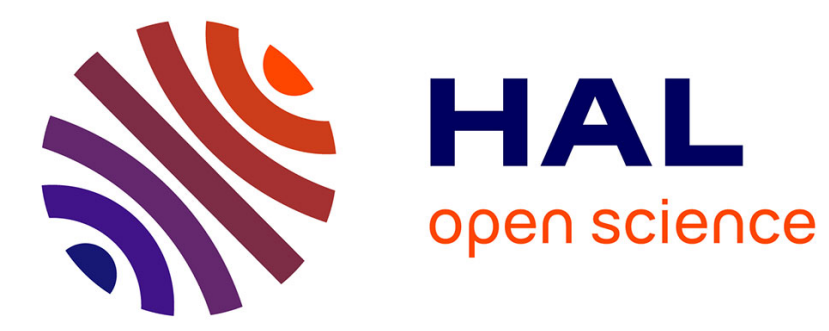

\title{
Dynamic heat transfer modeling of a closed refrigerated display cabinet
}

\author{
N. Chaomuang, Onrawee Laguerre, D. Flick
}

\section{To cite this version:}

N. Chaomuang, Onrawee Laguerre, D. Flick. Dynamic heat transfer modeling of a closed refrigerated display cabinet. Applied Thermal Engineering, 2019, 161, pp.17. 10.1016/j.applthermaleng.2019.114138 . hal-02609583

\section{HAL Id: hal-02609583 \\ https://hal.inrae.fr/hal-02609583}

Submitted on 21 Dec 2021

HAL is a multi-disciplinary open access archive for the deposit and dissemination of scientific research documents, whether they are published or not. The documents may come from teaching and research institutions in France or abroad, or from public or private research centers.
L'archive ouverte pluridisciplinaire HAL, est destinée au dépôt et à la diffusion de documents scientifiques de niveau recherche, publiés ou non, émanant des établissements d'enseignement et de recherche français ou étrangers, des laboratoires publics ou privés.

\section{다)(1) $(5$}

Distributed under a Creative Commons Attribution - NonCommerciall 4.0 International 
2 Heat properties of a hydrophilic carboxylate-based MOF for water adsorption applications

5 Shuqing Cui ${ }^{\mathrm{a}}$, Afsaneh Marandi ${ }^{\mathrm{b}}$, Gaëlle Lebourleux ${ }^{\mathrm{c}}$, Mireille Thimon $^{\mathrm{c}}$, Maxime Bourdon ${ }^{\mathrm{c}}$,

6 Chaoben Chen ${ }^{\mathrm{a}}$, Maria Inês Severino ${ }^{\mathrm{b}}$, Victoria Steggles ${ }^{\mathrm{b}}$, Farid Nouar $^{\mathrm{b}}$, Christian Serre $^{\mathrm{b}^{*}}$

8 b Institut des Matériaux Poreux de Paris, UMR 8004 CNRS, Ecole Normale Supérieure,

9 Ecole Supérieure de Physique et de Chimie Industrielles de Paris, PSL University, 75005 


\section{Abstract}

26 The development of new porous materials is expanding the boundaries of applications

27 related to gas adsorption, including gas separation, catalysis, drying and energy storage.

28 The specific heat capacity and thermal conductivity of the adsorbent materials are

29 important parameters in the engineering process. For instance, in the adsorptive heat pump technology, the energy generation and transfer by the adsorbent during the adsorption and desorption process of the adsorbate directly determines the energy efficiency of the working cycle. However, the thermal properties' data for the novel types of adsorbent materials, metal-organic frameworks (MOF), is often lacking in the literature. This work followed a protocol particularly relevant for the measurement of MOFs' thermal properties under powder form. A very promising hybrid material for energy storage, separation and other applications, MIL-160, has been tested as a reference. The specific heat capacity of the material was measured at temperatures ranging from $20{ }^{\circ} \mathrm{C}$ to $75{ }^{\circ} \mathrm{C}$ with a heat flow type differential scanning calorimeter (DSC). The thermal conductivity was measured with experimental data to the Clausius-Clapeyron model, the performance of this material in the application of adsorptive heat pump was obtained.

\section{Key words}

47 Metal-organic frameworks, specific heat capacity, thermal conductivity, adsorption, 48 thermodynamic efficiency 
51 The superior adsorption performance of modern porous solid materials incited the 52 development of various technologies including gas storage and separation, 53 dehumidification, cooling, and heating. In an adsorption process, the guest molecules 54 attach to adsorption sites on the surface of the host molecules, creating a relatively stable

55 phase by interactions of chemical bonds between the adsorbate and the adsorbent. The 56 adsorbent can later release the adsorbate when receiving external energy input. The whole 57 process involves a large amount of energy conversion under heat form, while porous solids 58 often have high specific heat capacity and low thermal conductivity due to open pore 59 structure and high pore volume, which often lead to a reduction in the sorption 60 performance.

61 As a new class of porous solids, metal-organic frameworks have aroused a great interest for 62 its potential in the immense possibilities of fine-tuned adsorptive properties [1]. Also, water 63 has been considered as the best green sorbate due to its broad applicability, non-toxicity 64 and large enthalpy during sorption. Since the discovery of water-stable MOFs, the 65 adsorption applications based on water-MOFs pairs have promoted cross-border research 66 between fundamental chemistry and thermal engineering [2][3][4]. The unique functions of 67 MOFs in tuning the hydrophilicity and water uptake show prospects in the improvement of 68 energy efficiency in specific working environment [5]. Variable concepts have made 69 progress in the aforementioned applications, especially in cooling [6][7][8], water 70 production[9][10][11][12] and drying[13][14][15].

71 The pore-filling step of water in MOF for the adsorption application in practice should be 72 reversible. Water molecules interact with the polar sites in MOF's structure via hydrogen 73 bonds, but not via strong coordination bonds within the frameworks. This pore-filling 74 mechanism is different from a typical chemisorption and can have a smaller adsorption 75 enthalpy close to the water evaporation heat. As a consequence, a strategy of developing 76 novel sorbents is to create ordered large pores to enhance the cyclic adsorption capacity 77 [16][17]. A higher fraction of void volume would result in undesirable heat properties that 78 have a negative impact on the cycling sorption performance.

79 The charging and discharging of thermal energy accompanying the cyclic ad-desorption 80 operations involves heat retention by the sorbents and thus a rapid temperature swing of the 81 MOFs. Because a miniscule movement along the step-wise sorption isotherms of MOFs 82 may engender a great amount of change in water uptake, precise measurement of specific 
heat capacity and thermal conductivity has a significant impact on the evaluation and prediction of the adsorption performance, especially in a dynamic modeling work. Yet very few values have been reported in the literature and most researchers adopt an average heat capacity of $1 \mathrm{~J} /(\mathrm{g}$. K). Huang et al.[18] have reported a thermal conductivity below $0.1 \mathrm{~W} /$ $\mathrm{m} \mathrm{K}$ of MOF-5 at room temperature after shaping, which is much lower than the single crystal. Purewal et al. [19] have showed that this value can increase by 5 times with $10 \mathrm{wt} \%$ graphite additives. Ming et al. [20] measured the specific heat capacity of MOF-5 as 0.72 $\mathrm{J} / \mathrm{g} \mathrm{K}$, similar to alumina and graphite. Erickson KJ et al.[21] found HKUST-1 composite with a thermal conductivity of $0.27 \mathrm{~W} / \mathrm{m} \mathrm{K}$. These results remain in the range of low heat transfer performance similar to conventional adsorbents such as zeolite type $\mathrm{X}$, zeolite type CHA, carbon- or silica-based matrix encapsulating phase change materials (PCM), etc.[22][23][24][25][26][27]

The differential scanning calorimetry is a dominant technique in the direct measurement of heat properties for its simple operation and wide adaptability to variable working conditions [28]. Frazzica et al. [29] developed a methodology to directly measure the heat transfer properties of AQSOA Z02 in an adsorptive heat pump application with similar techniques. BASF and co-workers [30] carried out the room temperature thermal conductivity test of MOF-5 for gas storage by a DSC and a xenon thermal flash diffusivity instrument. $\mathrm{Mu}$ and Walton [31] measured the specific heat capacity of several MOFs by using DSC coupled with a thermal gravimetric analyzer covering 50 to $200{ }^{\circ} \mathrm{C}$ to verify their thermal stability.

In this work, a simple method and protocol is presented for the measurement of heat transfer properties of MOF bulk materials for adsorption applications. The specific heat capacity and thermal conductivity are key parameters in the design of adsorptive based energy transformation devices. A hydrophilic Al furane dicarboxylic based MOF, MIL-160(Al), which is one of the most promising adsorbents to date in the storage and transformation of low-grade energy is taken as an example [32]. The thermal efficiency of an adsorptive heat pump employing the adsorbent is also derived.

\section{Experiments}

113 MIL-160(Al) was synthesized via an up-scale version of the process reported in a previous 114 study [32]. In short, $\mathrm{Al}(\mathrm{OH})\left(\mathrm{CH}_{3} \mathrm{COO}\right)_{2} \quad(0.6 \mathrm{~mol}, 93.7 \mathrm{~g} ;$ Aldrich, 90\%) and 
115 2,5-furandicarboxylicacid $(0.6 \mathrm{~mol}, 97.3 \mathrm{~g})$ were mixed in distilled water $(600 \mathrm{~mL})$ and 116 stirred under reflux condition for $24 \mathrm{~h}$. The mixture was filtered and washed with ethanol at 117 room temperature. The resulting white solid in powder form was dried under $100^{\circ} \mathrm{C}$, 118 yielding 111.5g activated MIL-160(Al) (90\%).

119 The Brunauer-Emmett-Teller (BET) surface calculations were carried out from N2 120 adsorption-desorption isotherms measured at liquid nitrogen temperature $(77 \mathrm{~K})$ after 121 dehydration under vacuum at $423 \mathrm{~K}$ for $12 \mathrm{~h}$ using Micromeritics Tristar 3020. The pore 122 volume was taken by a single point method at relative pressure $\left(\mathrm{p} / \mathrm{p}_{0}\right)=0.99$. The 123 high-resolution X-ray powder diffraction-pattern of MIL-160 was recorded in two hours 124 within the $4-60^{\circ} 2 \theta$ range, with a step of $0.002^{\circ}$ and a $\lambda$ equal to $1.540598 \AA$.

125 Water-sorption isotherms were measured by an intelligent dynamic vapor sorption instrument (DVS Vacuum, SurfaceMesurementSystems Ltd.) connected to a humidity

127 generator. The experiments were carried out in the temperature range of $20-60{ }^{\circ} \mathrm{C}$ at the relative vapour pressure precisely $(\mathrm{RH}=0-95 \%)$. The humidity was controlled by using two mass-flow controllers with dry air and pure vapour, respectively. The precise humidified airflow passed through two thermogravimetric balances with the sample in one and blank for another. Prior to the adsorption experiment, the samples were dehydrated at $150^{\circ} \mathrm{C}$ for $12 \mathrm{~h}$ under high vacuum $\left(<10^{-6}\right.$ torr $)$.

134 The specific heat capacity is directly linked to the thermal loss in an adsorption process 135 [33]. The DSC used in the experiment is $\mu \mathrm{SC}$, a Tian-Calvet type microcalorimeter 136 manufactured by Setaram Instrumentation, France. With this instrument, measurements can 137 be realized under isothermal conditions or with a constant heating rate ranging between 
0.001 and $1.2 \mathrm{~K} / \mathrm{min}$. A schematic representation of the DSC is shown in Fig. 1. It has a RMS noise level of $0.2 \mu \mathrm{W}$ typically. The temperature ranges from $-20^{\circ} \mathrm{C}$ to $170^{\circ} \mathrm{C}$, controlled precisely by a Peltier element based thermostat, that surround the sample on all sides. It is equipped with four calorimetric wells that enable two simultaneous tests for two samples and two references. The measurement cell is made of Hastelloy C276 with an internal volume of $850 \mu \mathrm{L}$ and is able to measure solid, liquid samples or blends. A bunch of Peltier elements are positioned around the cell to measure the temperature difference between the sample and the environment in 3D. This arrangement allows for measuring thicker samples on larger volume closer to real conditions.

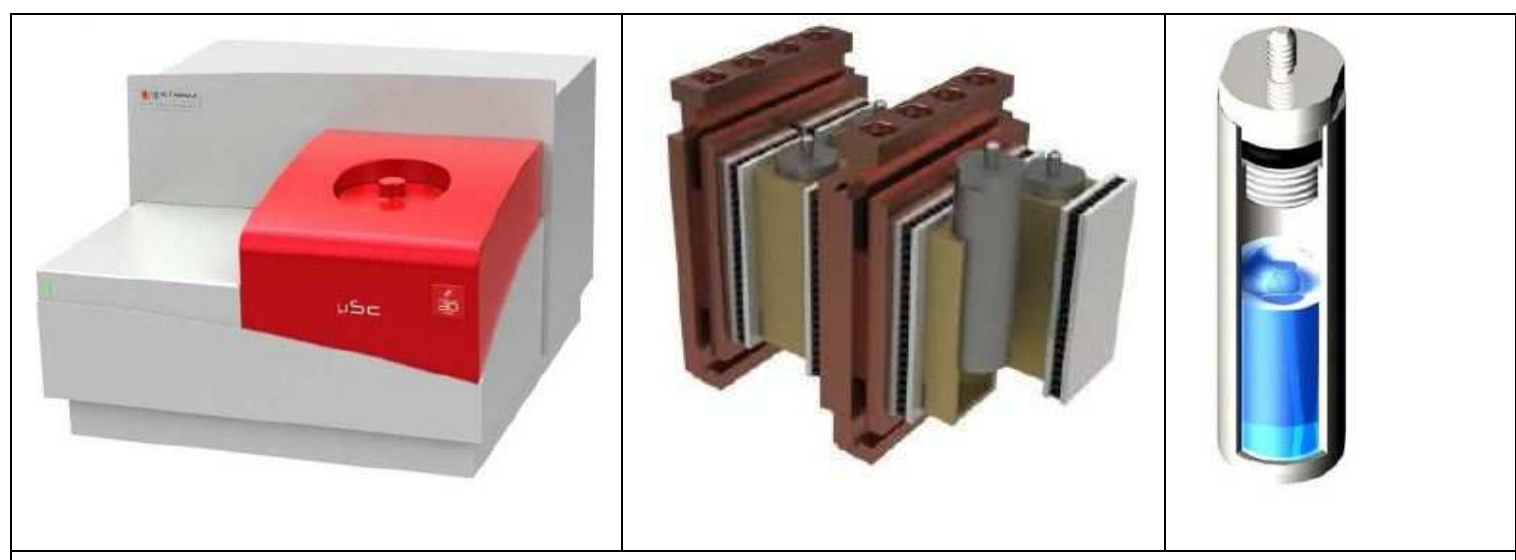

Figure 1. $\mu \mathrm{SC}$ experimental platform. Left: Setaram $\mu \mathrm{SC}$ Type Tian-Calvet. Middle: 4 calorimetric wells. Right: measurement cell

The determination of the specific heat capacity of MIL-160(Al) using the continuous

148 temperature programming method requires the realization of two different and successive 149 tests:

150 -a test with two empty cells (which will be called "blank");

151 -a test with the sample in the measurement cell and the reference cell remaining empty.

152 It is imperative to use the same "measurement" cell for both tests as well as an identical 153 temperature program.

154 To compare the impact of water sorption, both dry and fully loaded samples were measured.

155 For the loaded sample, before the test, the powder of MIL-160(Al) was saturated under an 
156 air-vapor mixing flow of $30 \% \mathrm{RH}$ at $20^{\circ} \mathrm{C}$ for 2 hours to ensure it achieved the uptake

157 equilibrium at this state. The sample was weighed and inserted into a batch cell. The

158 powder was carefully packed into the cell to ensure the homogeneity of the measured

159 sample. The initial mass was $400.85 \mathrm{mg}$.

160 The following experimental profile has been employed:

161 - stabilization at $20^{\circ} \mathrm{C}$ during 1800 s

162 - heating from $20^{\circ} \mathrm{C}$ to $75^{\circ} \mathrm{C}$ to $0.2^{\circ} \mathrm{C} / \mathrm{min}$

163 - stabilization at $75^{\circ} \mathrm{C}$ during $1800 \mathrm{~s}$

$164 \quad 2.3$ Thermal conductivity

165 Thermal conductivity is measured with a C-ThermTCi sensor from C-Therm, Canada. The

166 C-Therm TCi employs a modified Transient Plane Source technique. Instead of a common

167 used laser light heating source, a known current is applied to the sensor's spiral heating

168 element, providing a small amount of heat (Fig 2.). A guard ring around the sensor is

169 simultaneously charged to support a one-dimensional heat exchange between the primary

170 sensor coil and the sample. The current applied to the spiral element results in a rise in

171 temperature at the interface between the sensor and sample, which induces a change in the

172 voltage drop of the coil. The thermal diffusivity and conductivity is derived from the

173 temperature increasing curves versus heating time. The temperature increasing thus the

174 voltage rise is steeper for materials with lower thermal conductivity and flatter for higher

175 thermal conductivity. 


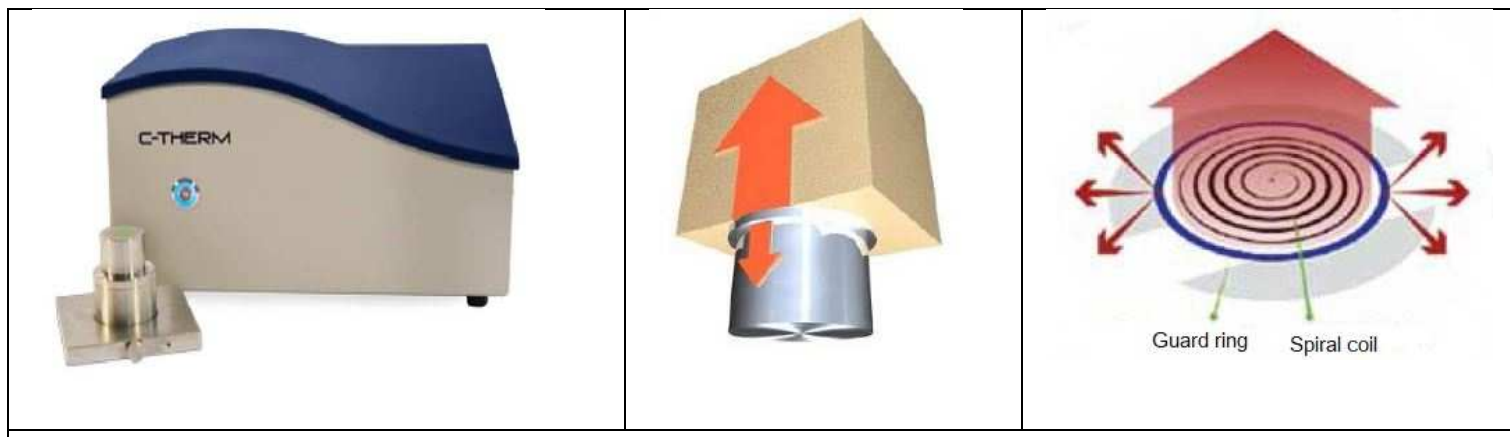

Figure 2. Thermal conductivity experimental platform.

The thermal conductivity is linked to the density of the sample. Powders of MIL-160(Al) have been compressed in to bloc under pressure. Again, a humid sample was obtained by saturating the packed powder under an air-vapor mixing flow of $30 \% \mathrm{RH}$ at a lower temperature for 2 hours to ensure it achieved the loading equilibrium at this state. The whole analysis instrument was placed in a small climate chamber to regulate the RH. A dry sample for comparison was obtained by heating the humid sample under $90^{\circ} \mathrm{C}$ for 2 hours.

\section{Results and discussion}

2.1 Characterization of MIL-160(Al)

After purification and activation, the BET specific surface area and pore volume of the sample were found to be $1200 \mathrm{~m}^{2} / \mathrm{g}$ and $0.398 \mathrm{~cm}^{3} / \mathrm{g}$ respectively (Fig 3a).The PXRD pattern and thermalgravimetric of the MIL-160(Al) powder (Fig 3b,c) are consistent with previously synthesized with small scale process reported in [32]. Water adsorption isotherms for MIL-160 are step-wise curves with reflection point at around $8 \% \mathrm{P} / \mathrm{P}_{0}$ and the majority uptake (>90\%) is complete at $20 \% \mathrm{P} / \mathrm{P}_{0}$ (Fig 3d). The position of adsorption stage varies very little under different temperature and can be neglected as we only focused on the full uptake conditions. The maximum uptake at $\mathrm{P} / \mathrm{P}_{0}=0.9$ reaches around $0.4 \mathrm{~g} / \mathrm{g}$ dry mass. There is barely sorption hysteresis at all temperatures so that the adsorption and desorption routines almost coincide with each other which is an advantage to be integrated into an active mechanic system. The isosteric heat $\Delta \mathrm{H}_{\mathrm{ads}}$ of water adsorption can be 
196 given by [35]:

$$
\Delta H_{a d s}(T)=\mathrm{R}\left(\frac{\mathrm{d}(\ln \mathrm{P})}{\mathrm{d}\left(-\frac{1}{\mathrm{~T}}\right)}\right)_{w}
$$

197 Where $\Delta \mathrm{H}_{\mathrm{ads}}, \mathrm{R}, \mathrm{P}, \mathrm{T}$ and $w$ represent the isosteric enthalpy of adsorption, universal gas constant, pressure, temperature, and water uptake. The isosteric enthalpy of adsorption is obtained as a function of water uptake and adsorption isotherms measured across a wide temperature range with a linear interpolation method. The $\Delta \mathrm{H}_{\mathrm{ads}}$ drops very quickly to 50 $\mathrm{kJ} / \mathrm{mol}$ at the water uptake $w=0.02 \mathrm{~g} / \mathrm{g}$ dry mass, maintains this value until $0.3 \mathrm{~g} / \mathrm{g}$ dry mass and varies a little thereafter. This plateau of the $\Delta \mathrm{H}_{\mathrm{ads}}$ indicates reversible adsorption-desorption phenomena.

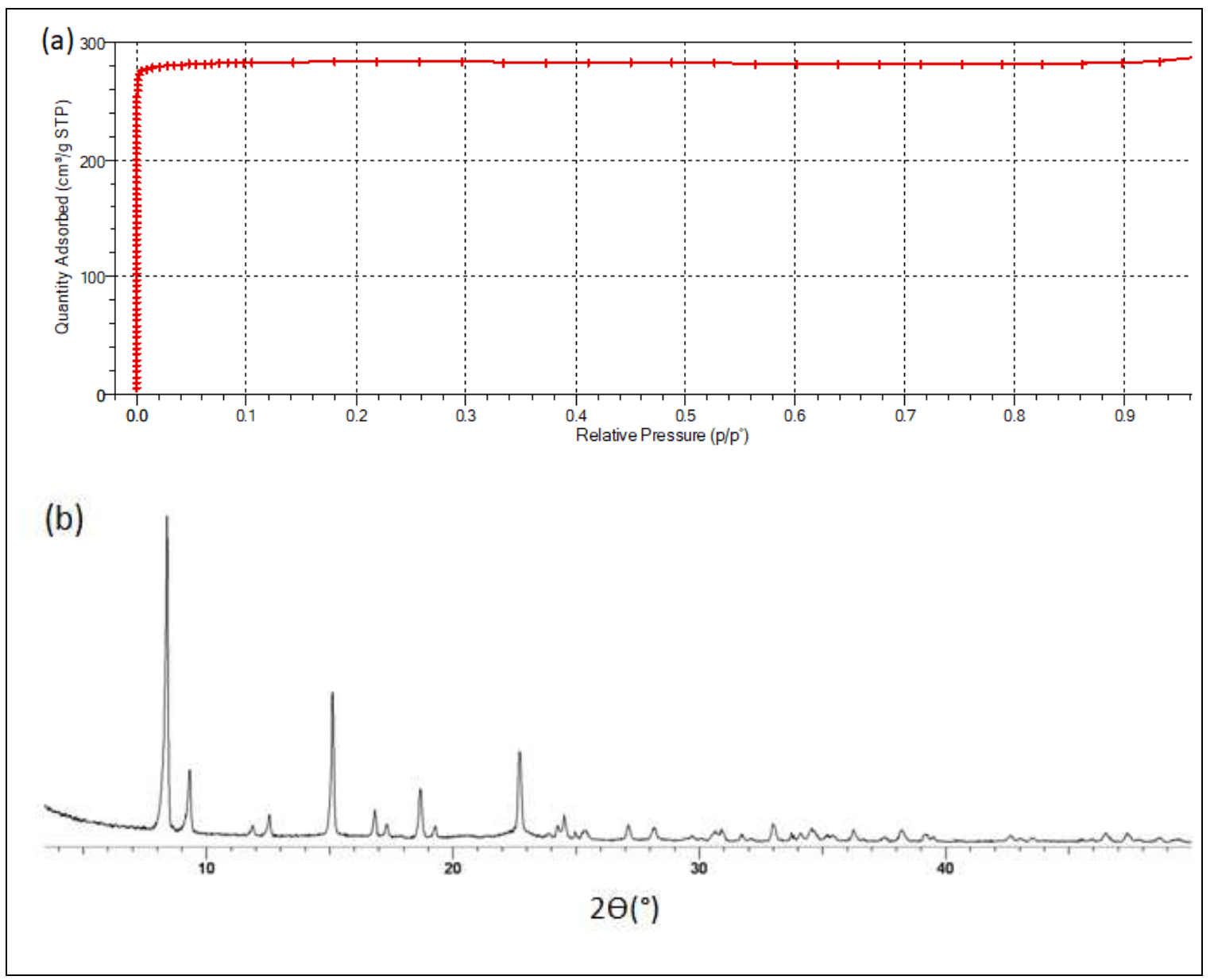



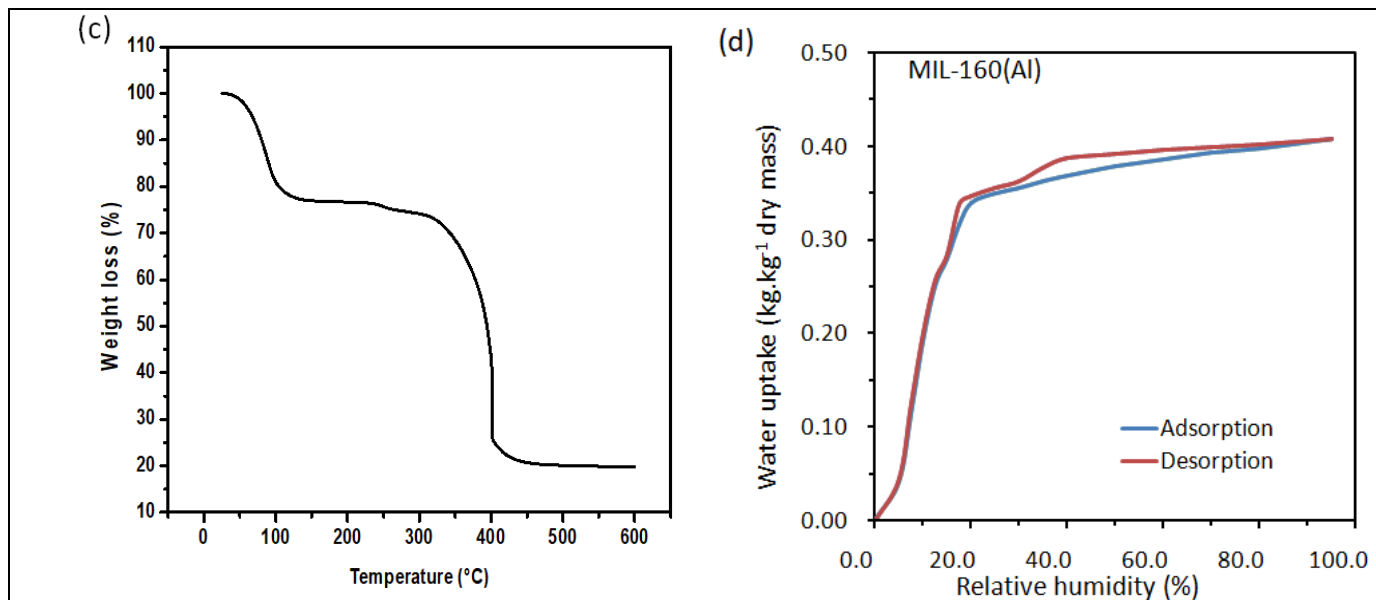

Figure 3. Characterization of MIL-160(Al). (a) Nitrogen gas sorption isotherm. (b) Powder X-Ray diffraction pattern $(\lambda \mathrm{Cu} \approx 1.5406 \AA)$ (c) Thermogravimetric analysis under air atmosphere (heating rate of $3^{\circ} \mathrm{C} / \mathrm{min}$ ) (d) Water vapor sorption isotherm at $298 \mathrm{~K}$

Flow signal $A_{s}$ and $A_{b}(\mu V)$ at temperature $T$ of the sample and blank, respectively.

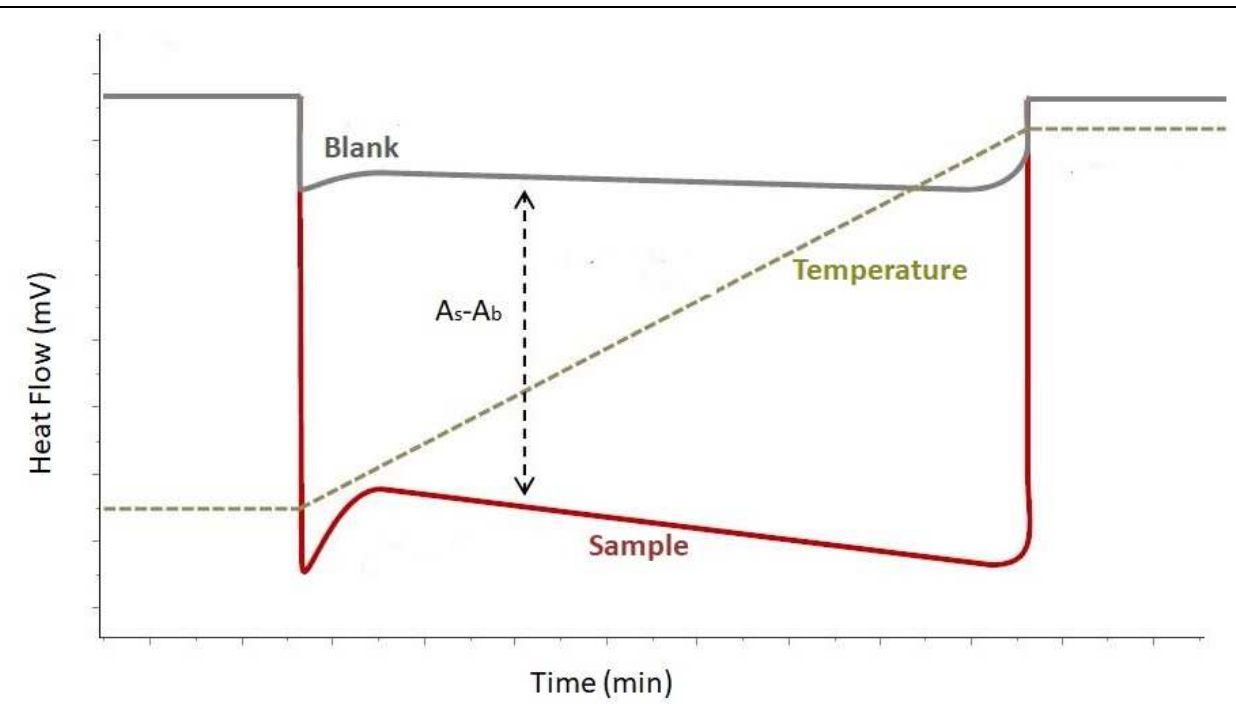

Figure 4. Thermograms superposition of blank and sample 
The heat capacity of the sample can be calculated as the following equation:

$$
C_{p}(T)=\frac{\mathrm{A}_{\mathrm{s}}-\mathrm{A}_{\mathrm{b}}}{\mathrm{m}_{\mathrm{s}} \frac{\mathrm{dT}}{\mathrm{dt}}}
$$

where $C_{p}(T)$ is the heat capacity of the sample in $J /(g . K)$ at a temperature $T$; $A_{s}$ and $A_{b}$ are sample and blank output signals in $\mu \mathrm{V} ; \mathrm{m}_{\mathrm{s}}$ is mass of the sample in $\mathrm{mg} ; \frac{\mathrm{dT}}{\mathrm{dt}}$ is the heating rate in $\mathrm{K} / \mathrm{s}$.

The experimental conditions were adopted to measure a representative sample of $400 \mathrm{mg}$ on macroscopic level and minimize the impact of the heating rate. The calculation of $C_{p}$ was carried out from 20 to $75^{\circ} \mathrm{C}$ that is the operational temperature range of MIL-160(Al) for an adsorption heat pump system. The measured result of the highly loaded sample on each point of this temperature range is shown in Fig 5. The measured specific heat capacity remains almost constant with a slight increase by $3 \%$ over the temperature range.

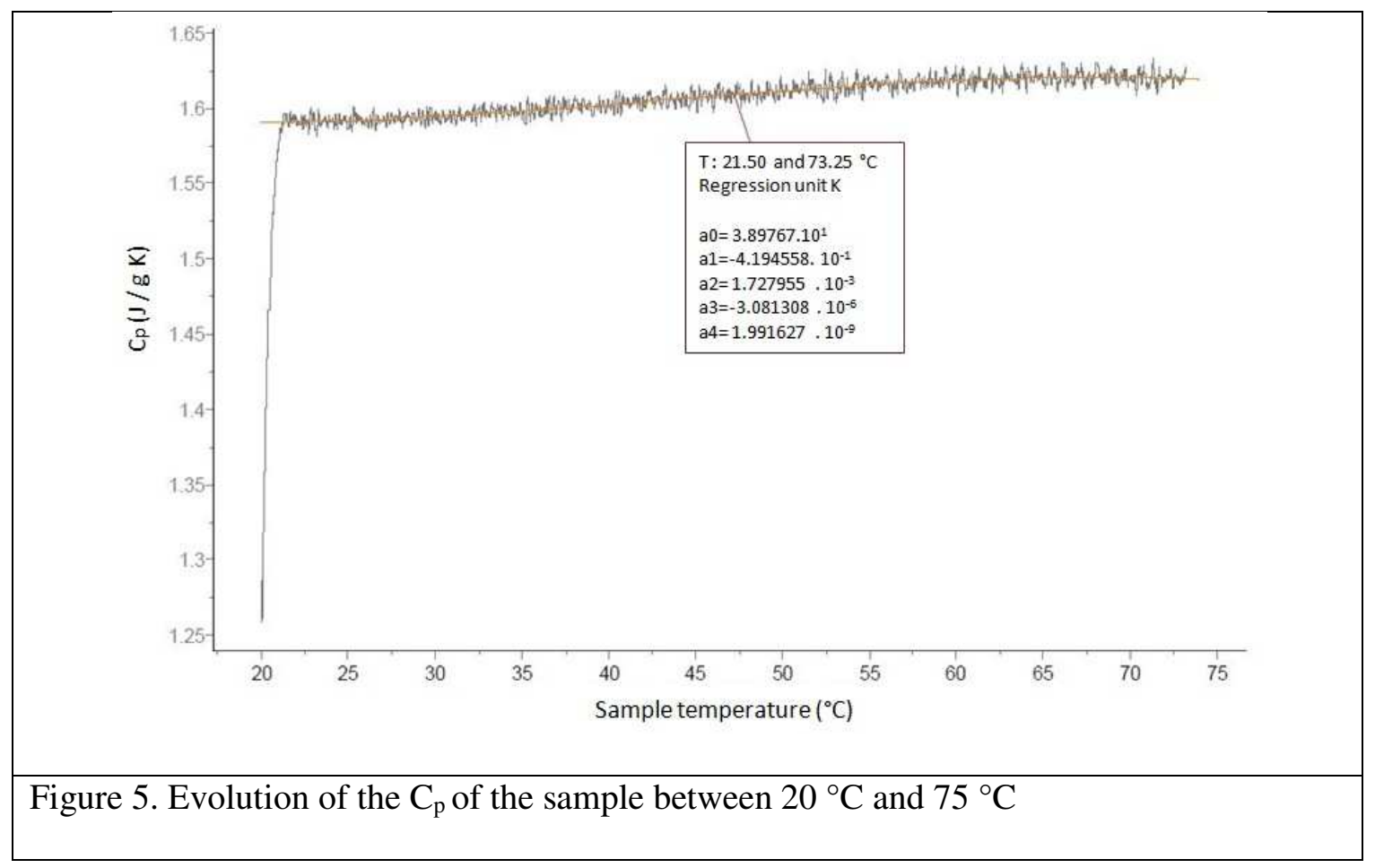


Table 1. Comparison of the heat capacity between dry and highly loaded samples,

\begin{tabular}{|l|c|c|c|}
\multicolumn{4}{|c|}{ measured $\mathrm{C}_{\mathrm{p}}$ in $\mathrm{J} /(\mathrm{g} . \mathrm{K})$} \\
\hline \multicolumn{1}{|c|}{ Sample } & $24.8^{\circ} \mathrm{C}$ & $45.0^{\circ} \mathrm{C}$ & $70.0^{\circ} \mathrm{C}$ \\
\hline Highly loaded & 1.588 & 1.605 & 1.617 \\
\hline Dry & 1.117 & 1.125 & 1.160 \\
\hline
\end{tabular}

220 The more water the MOF contains, the higher its specific heat capacity. A reduction of $30 \%$

221 on the $\mathrm{C}_{\mathrm{p}}$ can be observed when the desorption is complete on the loaded sample. In a

222 typical thermodynamic cycle of the adsorption heat pump, the sorbents with higher water

223 uptake is often heated to desorption temperatures with external energy input and the

224 released heat during temperature decreasing is to be evacuated. The necessary energy cost

225 to power the cycling operation would be higher when using the heat capacity measured at

226 different uptake state than in a calculation based only on the value of dry materials.

The thermal conductivity of the sample can be calculated from the following equation:

$$
e=\sqrt{k \rho C_{p}}
$$

where $e$ is the thermal effusively in $\mathrm{W} \cdot \mathrm{s}^{1 / 2} /\left(\mathrm{m}^{2} . \mathrm{K}\right), k$ is thermal conductivity in $\mathrm{W} /(\mathrm{m} . \mathrm{K}), \rho$

230 is the density in $\mathrm{kg} / \mathrm{m}^{3}$.

231 The calculated thermal conductivity of one sample was shown in Table 2, which slightly

232 decreased with temperature increasing for each state of water uptake. The average values

233 are similar to conventional sorbents. The case of Loaded sample was saturated at $25^{\circ} \mathrm{C}$ and

$23430 \% \mathrm{RH}$. The relative humidity in the environment maintained at $30 \%$ when increasing the temperature so that water uptake would not have an evident change. The case of Dry sample was for dried adsorbent with less than 5\% RH at different temperature. The case of 
Open system was the saturated sample undergoing the increase of temperature in an open environment so that the RH decreased accordingly. As the saturated MIL-160(Al) can be completely regenerated below $90{ }^{\circ} \mathrm{C}$ in either open or closed mechanic systems, results at three typical temperatures were listed to demonstrate the measurement of its thermal conductivity: $25{ }^{\circ} \mathrm{C}$, the hydrophilic MIL-160(Al) is easily saturated; $40^{\circ} \mathrm{C}$, the vapour starts to be released in an open system; $70^{\circ} \mathrm{C}$, desorption is complete in an open system A drop of thermal conductivity by $15 \%$ in average was obtained when vapour is completely desorbed from the saturated sample.

Table 2. Comparison of the thermal conductivity between dry and highly loaded samples,

\begin{tabular}{|l|c|c|c|c|c|c|}
\hline \multirow{2}{*}{ Sample 1 } & \multicolumn{2}{|c|}{$25.4^{\circ} \mathrm{C}$} & \multicolumn{2}{c|}{$43.6^{\circ} \mathrm{C}$} & \multicolumn{2}{c|}{$72.3^{\circ} \mathrm{C}$} \\
\cline { 2 - 7 } & $\begin{array}{c}\text { Effusivity } \\
\left(\mathrm{Ws}^{1 / 2} / \mathrm{m}^{2} . \mathrm{K}\right)\end{array}$ & $\begin{array}{c}k \\
(\mathrm{~W} / \mathrm{m} . \mathrm{K})\end{array}$ & $\begin{array}{c}\text { Effusivity } \\
\left(\mathrm{Ws}^{1 / 2} / \mathrm{m}^{2} . \mathrm{K}\right)\end{array}$ & $\begin{array}{c}k \\
(\mathrm{~W} / \mathrm{m} . \mathrm{K})\end{array}$ & $\begin{array}{c}\text { Effusivity } \\
\left(\mathrm{Ws}^{1 / 2} / \mathrm{m}^{2} . \mathrm{K}\right)\end{array}$ & $\begin{array}{c}k \\
(\mathrm{~W} / \mathrm{m} . \mathrm{K})\end{array}$ \\
\hline Loaded & 172.173 & 0.071 & 160.732 & 0.069 & 157.723 & 0.068 \\
\hline Dry & 131.356 & 0.061 & 129.141 & 0.061 & 127.240 & 0.060 \\
\hline open system & 171.189 & 0.071 & 160.617 & 0.068 & 127.206 & 0.060 \\
\hline
\end{tabular}

245 The packed density also impacts the thermal conductivity. The measured thermal 246 conductivity of differently packed powder is shown in Table 3 . The packed density and thickness was closed to the operational conditions where the effect due to macroscopic void volume was also taken into consideration.

Table 3. Impact of the compression force on the thermal conductivity

\begin{tabular}{|l|c|c|c|c|}
\hline & Temperature & $\begin{array}{c}\text { Packed } \\
\text { pressure }\end{array}$ & Test condition & $\begin{array}{c}k \\
(\mathrm{~W} / \mathrm{m} . \mathrm{K})\end{array}$ \\
\hline Loaded 1 & $25.4^{\circ} \mathrm{C}$ & $3.5 \mathrm{kPa}$ & loosely & 0.071 \\
\hline Loaded 2 & $25.3^{\circ} \mathrm{C}$ & $3.5 \mathrm{kPa}$ & $3.5 \mathrm{kPa}$ & 0.078 \\
\hline Loaded 3 & $25.3^{\circ} \mathrm{C}$ & $3.5 \mathrm{kPa}$ & $12.95 \mathrm{kPa}$ & 0.108 \\
\hline Loaded 4 & $26.1^{\circ} \mathrm{C}$ & $3.5 \mathrm{kPa}$ & $25.91 \mathrm{kPa}$ & 0.117 \\
\hline bead $_{0.4-0.6 \mathrm{~mm}}$ & $26.5^{\circ} \mathrm{C}$ & - & loosely & 0.065 \\
\hline
\end{tabular}

250 The packed pressure of the powder layer was $3.5 \mathrm{kPa}$ and the samples were tested with 251 different level of external compression. A shaped sample under bead form with size of 0.4 252 to $0.6 \mathrm{~mm}$ was shown to represent the realistic condition in the application of adsorption 253 heat pump. The effective thermal conductivity of the beads is close to the loosely 254 compacted powder which is a quite low value. 
255 Since a low conductivity has a negative impact in the dynamic performance of the sorption 256 cycle, different strategies could be followed to improve the thermal efficiency, such as 257 packing the powder with higher bulk density, shaping the powder with variable binders (e.g. 258 silicate), and mixing in highly conductive additives (e.g. graphite, thermal conductivity $2591400 \mathrm{w} /(\mathrm{m} . \mathrm{K})$, heat capacity $0.7 \mathrm{~J} /(\mathrm{g} . \mathrm{K})$ in the same temperature range). However, the 260 additives will sacrifice the power density and energy storage density of the MOF in a 261 mechanic system, thus requiring further optimization in different working environment. 262 The pursuing in very high packed density is not recommended because of the drawback 263 that the mass transfer becomes weaker which lowers the specific power. In practice, it is 264 advised to coat the powder on the highly conductive surface to improve heat transfer.

2652.4 Thermodynamic efficiency for adsorption cooler based on MIL-160(Al)

266 The above-measured values of adsorptive and thermal properties allow the accurate 267 calculation of the coefficient of performance (COP) for an adsorption cooler device based 268 on MIL-160(Al). The operational temperatures were chosen as $5^{\circ} \mathrm{C}$ for the evaporator, $26930^{\circ} \mathrm{C}$ for the condenser and $85^{\circ} \mathrm{C}$ for the desorption process. The water adsorption isosteres 270 derived from the isotherms were mapped in to a Clausius - Clapeyron diagram as shown in 271 Fig. 5. The adsorbent exchanged water $\Delta w$ by more than $30 \mathrm{wt} \%$ dry mass via a cyclic 272 sorption process. The hydrophilic nature enables a typical evaporation temperature of $2735-7^{\circ} \mathrm{C}$. The desorption temperature below $90^{\circ} \mathrm{C}$ allows the use of low-grade heat source. 274 MIL-160(Al) is approved as one of the most promising adsorbents for this application in 275 the literature. 


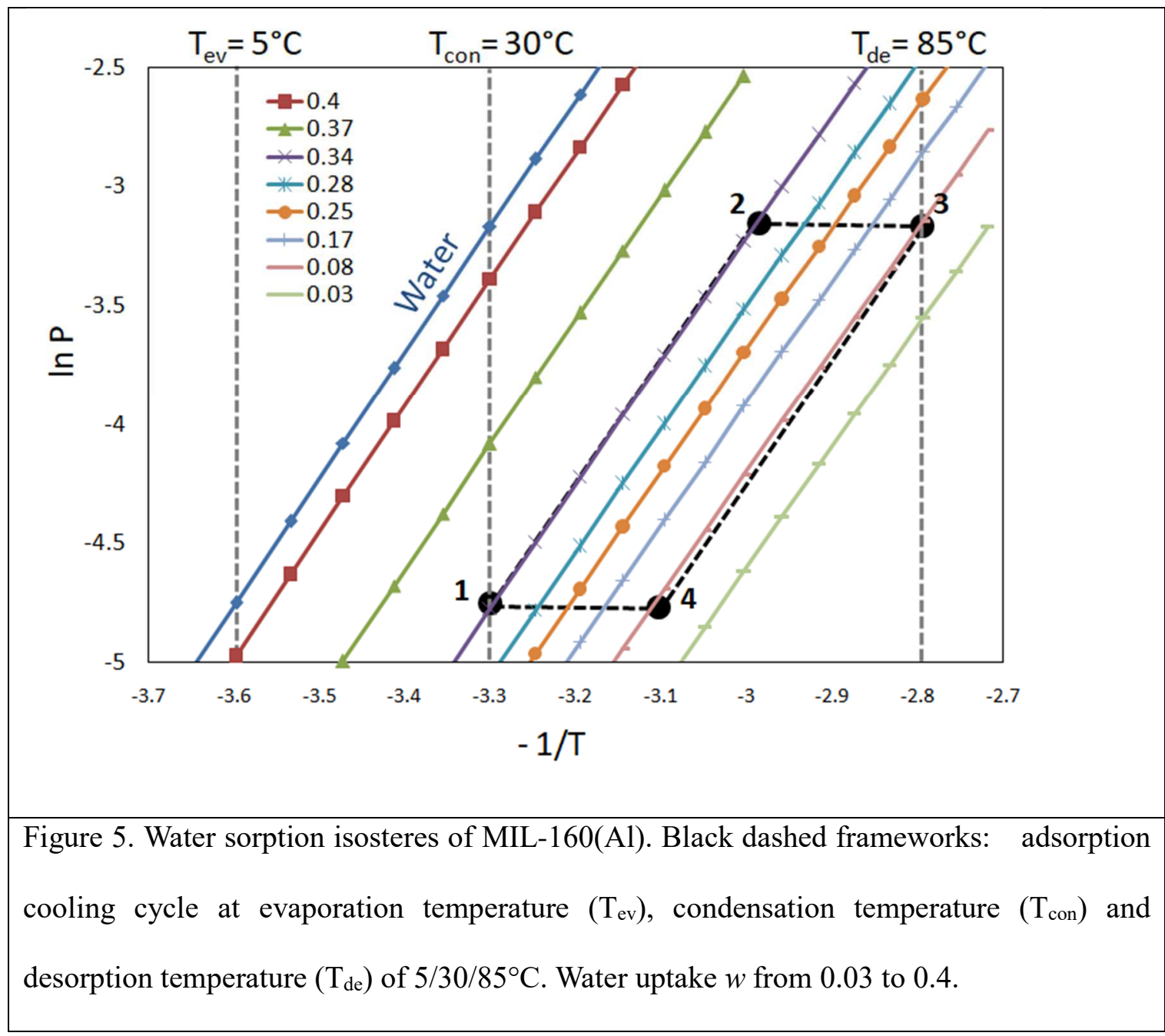

The COP of the adsorption cooling cycle is calculated as the ratio of cold energy produced

to the heat consumed during the isosteric heating and isobaric desorption [7].

$$
\mathrm{COP}=\frac{\mathrm{Q}_{\mathrm{ev}}}{\mathrm{Q}_{\mathrm{ist}}+\mathrm{Q}_{\mathrm{de}}}
$$

This equation can be expressed as the refrigerant (water) evaporation heat over the sum of

279 the specific heating process $\left(\mathrm{Q}_{\text {ist }}\right)$ and the latent heat of desorption process $\left(\mathrm{Q}_{\mathrm{de}}\right)$. Assuming 280 in adsorption and desorption, the adsorbent reaches thermodynamic equilibrium state at 281 given temperature and pressure, the $\mathrm{COP}$ of the operational cycles of $5 / 30 / 85^{\circ} \mathrm{C}$ is 0.76 . On 282 the contrary, if the values of the heat properties were taken for the dry MOF, the 283 corresponding calculation on the COP would render 0.79 , with a positive deviation of $4 \%$. 284 The COP value makes MIL-160(Al) highly competitive to most conventional and 285 innovative sorbents in the application of water adsorption cooling such as SAPO-34, 


\section{Conclusions}

In this work, a simple method that measures the heat properties of bulk porous materials is applied on MIL-160(Al), an hydrophilic MOF highly performant in water vapor adsorption processes. Both the thermal capacity and conductivity of the MOF was measured with high resolution and accuracy in the common working range of an adsorption cooler. The specific heat capacity of MIL-160(Al) demonstrated a slightly incremental tendency with temperature. The heat capacity is undesirably higher than the commonly used zeolites such as SAPO-34, TAPSO, and their thermal conductivity is quite close. However, this difference has little impact on the COP of a thermal driven adsorption process given the fact that the adsorption enthalpy is two orders of magnitude larger.

Since water adsorption was proven to become a more and more important subject in both fundamental research and technology development thanks to the rapid development of innovative sorbents, the method and protocol presented here will serve as a reference technique to characterize the key thermal properties of the adsorbents in various sorption systems.

\section{Acknowledgements}

\section{References}

[1] G. Maurin, C. Serre, A. Cooper, G. Ferey, The new age of MOFs and of their porous-related solids.Chem. Soc. Rev. 46 (2017) 3104-3107, 